\title{
Protection by sterols against the cytotoxicity of syringomycin in the yeast Saccharomyces cerevisiae
}

\author{
Charnchai Julmanop, ${ }^{1}$ Yoshiniko Takano, ${ }^{1}$ Jon Y. Takemoto ${ }^{2}$ and Tokichi Miyakawa ${ }^{1 *}$ \\ ${ }^{1}$ Department of Fermentation Technology, Hiroshima University, Higashi-Hiroshima, 724 Japan \\ ${ }^{2}$ Department of Biology and Molecular Biology Program, Utah State University, Logan, Utah 84322-5305, USA
}

(Received 12 February 1993; revised 1 April 1993; accepted 4 May 1993)

\begin{abstract}
A brief exposure ( $\mathrm{ca} 20 \mathrm{~min}$ ) of the yeast Saccharomyces cerevisiae to the phytotoxin syringomycin was sufficient to kill the cell. The protective effect of sterols against this cytotoxicity of syringomycin was investigated. Syringomycin was much more toxic to growing cells than to stationary-phase cells. The cytotoxicity of syringomycin was reduced in an environment containing sterols. Cytotoxicity of syringomycin at $3 \mu \mathrm{g} \mathrm{ml}^{-1}$ (ca $2.5 \mu \mathrm{M})$ was completely abolished by the simultaneous presence of $10 \mu \mathrm{M}$-cholesterol in the medium. Cholesterol acetate had no protective effect. Ergosterol, sitosterol and stigmasterol also protected against syringomycin, but they were less effective than cholesterol. The protective effect of sterols against the action of syringomycin is consistent with our hypothesis that membrane ergosterol is a critical component for syringomycin-binding as suggested by recent genetic studies.
\end{abstract}

\section{Introduction}

The phytotoxin syringomycin, a lipodepsipeptide with an $M_{\mathrm{r}}$ value of 1226 , is produced by the bacterial plant pathogen Pseudomonas syringae pv. syringae and is a major virulence factor in plant diseases caused by this organism (Gross et al., 1977; Sinden et al., 1971). Syringomycin is a significant contributor to a variety of plant diseases (DeVay et al., 1968; Sinden et al., 1971). Application of a partially purified preparation of the toxin to young peach trees gave typical disease symptoms. The diseases caused by this bacterium include necroses of stone fruits and cowpea and holcus spot disease of maize (Gross \& DeVay, 1977). In addition to contributing to plant diseases, syringomycin inhibits the growth of several fungi including the yeast Saccharomyces cerevisiae (Zhang \& Takemoto, 1986, 1987).

As expected from the amphipathic structure of syringomycin, the host plasma membrane is the primary site of action of the toxin. Plant and yeast cells respond to the toxin similarly (Reidl \& Takemoto, 1987). Among the effects on the membrane are release of various cations, increase in membrane potential, $\mathrm{H}^{+}$-ATPase activity and protein phosphorylation (Bidwai \& Takemoto, 1987). By molecular genetic studies of the mechanism of action of syringomycin on $S$. cerevisiae, we

\footnotetext{
*Author for correspondence. Tel. 81824227196 ; fax 8182422 7191.
}

recently found that the yeast gene $S Y R I$ that complements the phenotype of a resistant mutant syr 1 , is identical with $E R G 3$ that encodes sterol C-5 desaturase, an enzyme of ergosterol biosynthesis (N. Taguchi and others, unpublished results). This suggested to us that ergosterol, a major component of the plasma membrane accounting for about $15 \%$ of the membrane lipids (Longley et al., 1968), is the possible target of the toxin. A null mutant of syrl did not contain ergosterol in the membrane, but was viable and resistant to syringomycin. Furthermore, a mutant lacking ergosterol (e.g. syr 1) had a significantly decreased syringomycin-binding ability. To examine the hypothesis that membrane ergosterol is critical for binding syringomycin, we studied the effect of externally added sterols on the cytotoxicity of syringomycin.

\section{Methods}

Yeast strains and growth conditions. Wild-type isogenic diploid S. cerevisiae strain RAY-3A-D (MATa/ $/$ leu2ura3his3trpI) was described by Tanaka et al. (1988). A syringomycin-resistant mutant YT1-b with a null allele of $S Y R 1 / E R G 3(s y r 1-\Delta 1)$ was prepared. In brief, a $300 \mathrm{bp} S a I I-S a l I$ region within the open reading frame of $S Y R I$ was replaced with the SalI-SmaI fragment of the HIS3 gene. The onestep gene disruption of the diploid strain RAY-3A-D was performed by transformation with the disrupted DNA fragment, and gene disruption was confirmed by Southern hybridization.

Syringomycin purification. Syringomycin (E-form) was purified to homogeneity as described previously (Bidwai \& Takemoto, 1987). 
Assay of the growth inhibition of $S$. cerevisiae by syringomycin. Exponentially-growing $S$. cerevisiae wild-type strain RAY-3A was inoculated at a cell concentration of $1 \times 10^{6}$ cells ml-1 into YPD medium containing $3 \mu \mathrm{g}$ syringomycin $\mathrm{ml}^{-1}$ and various concentrations of sterols. The cells were grown at $28^{\circ} \mathrm{C}$ in aerobic conditions with shaking. The growth of the culture was monitored by measuring $\mathrm{OD}_{660}$ every $2 \mathrm{~h}$.

Assay of the cytotoxicity of syringomycin on $S$. cerevisiae. Exponentially-growing $S$. cerevisiae cells were harvested after $8 \mathrm{~h}$ cultivation at $28^{\circ} \mathrm{C}$ in YPD medium $\left(\mathrm{ca} 5 \times 10^{7}\right.$ cells $\left.\mathrm{ml}^{-1}\right)$ and used for assay of cytotoxicity. Stationary-phase cells were harvested after $36 \mathrm{~h}$ cultivation $\left(\mathrm{ca} 1 \times 10^{9}\right.$ cells $\left.\mathrm{ml}^{-1}\right)$ and used when required. Syringo-

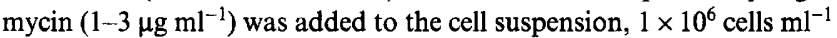
in YPD medium or saline $(0.85 \% \mathrm{NaCl})$ in sterile test tubes. After incubation for the indicated times at $28^{\circ} \mathrm{C}$ with shaking, a $0.1 \mathrm{ml}$ sample was taken and immediately diluted in $4.9 \mathrm{ml}$ ice-cold saline and plated on YPD medium after an appropriate dilution. The colonies were counted after incubation for $48 \mathrm{~h}$. To test the effect of sterols and other lipids on cytotoxicity, syringomycin $\left(1 \mu \mathrm{g} \mathrm{ml}^{-1}\right)$ and indicated amounts of various lipids were mixed. Incubation was initiated by the addition of exponentially growing yeast cells to the mixture. Samples were taken periodically and viable cells were counted as described above.

\section{Results}

Effect of sterols on growth inhibition of S. cerevisiae by syringomycin

First, we examined the effects of sterols on the growth inhibiting activity of syringomycin. The growth of $S$. cerevisiae cells in YPD medium in the presence of syringomycin and sterols was monitored by measuring the culture $\mathrm{OD}_{660}$ (Fig. 1). The growth of wild-type haploid strain RAY-3A was completely inhibited by the presence of syringomycin at $3 \mu \mathrm{g} \mathrm{ml}^{-1}$ (ca $2.5 \mu \mathrm{M}$ ) in the culture medium. Under the same conditions, the growth of an ergosterol-deficient syr l- $\Delta 1$ mutant was unaffected (data not shown). As expected from our hypothesis, the growth of wild-type cells in the medium containing syringomycin was restored by the simultaneous presence of exogenous sterols, such as ergosterol or cholesterol. The protective effect of the sterols was dose-dependent. The effect of cholesterol was more potent than ergosterol. In the presence of $3 \mu \mathrm{g}$ syringomycin $\mathrm{ml}^{-1}$ and $25 \mu \mathrm{M}$ cholesterol, the growth of the sensitive cells was restored to a level similar to that without syringomycin. In contrast, ergosterol only partially restored growth even at $50 \mu \mathrm{M}$, the solubility limit for this sterol in water. The added sterols had no effect on the growth rate (data not shown).

\section{Cytotoxicity of syringomycin on yeast cells}

Since syringomycin very rapidly affects the homeostasis of cellular $\mathrm{Ca}^{2+}$ and other ions, it was expected that syringomycin would decrease cell viability shortly after exposure of the cells to the toxin. This possibility was examined by determination of cell viability after incubation of the cells with syringomycin in YPD medium for various periods of time (Fig. 2). Cytotoxic effects were observed by treating the cells in YPD with concentrations of syringomycin of $1 \mu \mathrm{g} \mathrm{ml}^{-1}$ or higher. The cytotoxic effect was established rapidly on exposure of the cells to syringomycin, and viability was almost lost after about $20 \mathrm{~min}$ of incubation in YPD with $2 \mu \mathrm{g} \mathrm{ml}^{-1}$ of the toxin. The cytotoxicity of syringomycin was much higher when it was measured in saline instead of YPD (Fig. 2). The viability of the ergosterol-deficient mutant (syr 1- -1$)$ was unaffected by syringomycin under these conditions (data not shown).

We next compared the effect of syringomycin on exponentially growing cells and stationary-phase cells to

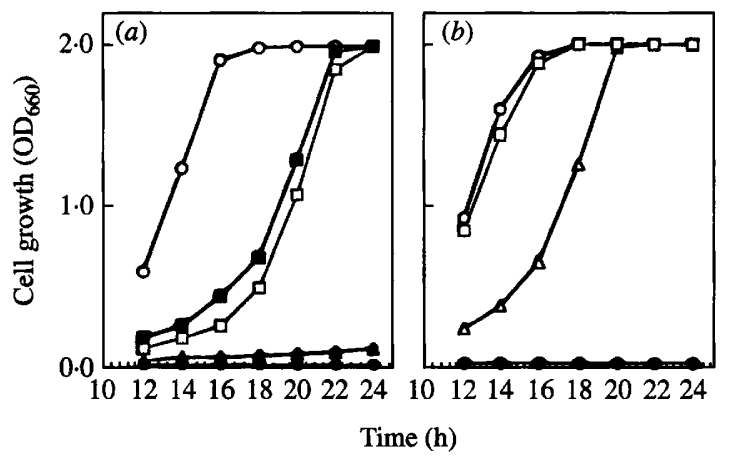

Fig. 1. Protection by sterols against the growth inhibition of $S$. cerevisiae cells by syringomycin. The growth of wild-type $S$. cerevisiae cells in YPD medium at $28^{\circ} \mathrm{C}$ in the absence of syringomycin (O), or in the presence of $3 \mu \mathrm{g}$ syringomycin $\mathrm{ml}^{-1}$ (ca $2.5 \mu \mathrm{M}$ ) and various concentrations of ergosterol $(a)$ or cholesterol $(b)$ was monitored by measuring $\mathrm{OD}_{660}$. The experiment was done 4 times with reproducible results. Results presented are from a representative single experiment. The concentrations of the sterols added were: $0(\Theta), 5(\Delta), 10(\triangle)$, $25(\square)$ and $50(\square) \mu \mathrm{M}$.

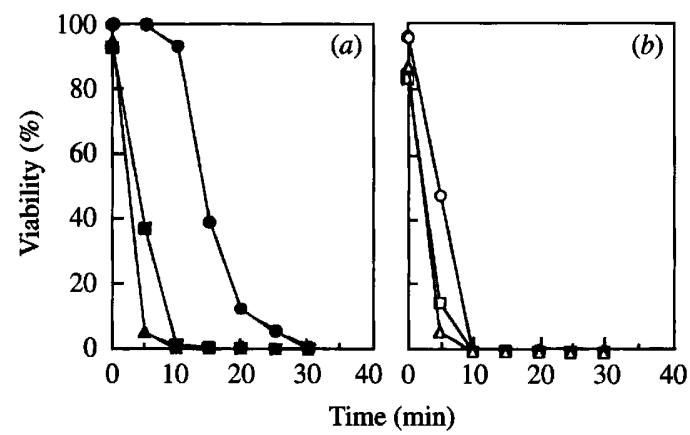

Fig. 2. Effect of incubation time on cytotoxicity of syringomycin. The cells were incubated at $28^{\circ} \mathrm{C}$ for various periods of time $(0-30 \mathrm{~min})$ in YPD medium $(a)$ or saline $(b)$ containing $1(0, O), 2(\square, \square)$ or $3(\Delta, \Delta) \mu \mathrm{g}$ syringomycin $\mathrm{ml}^{-1}$. At the end of incubation, the cells were immediately diluted with ice-cold saline, and viable cells were determined by plating the cells on YPD plates. The experiment was done twice with reproducible results. Results presented are from a representative single experiment. 


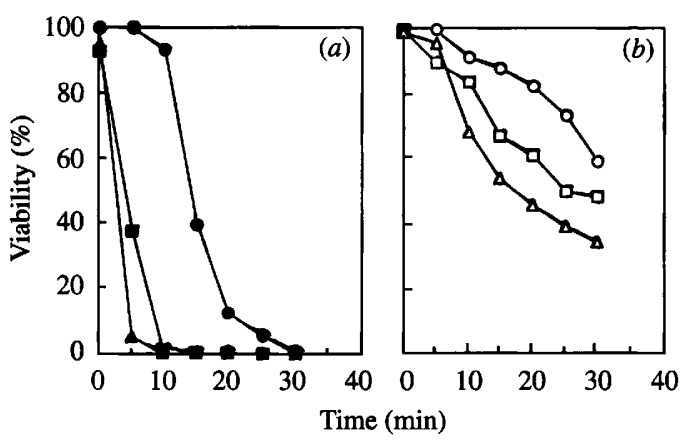

Fig. 3. Comparison of cytotoxicity of syringomycin on exponentially growing cells and stationary-phase cells. Exponentially growing cells $(a)$ and stationary-phase cells $(b)$ were incubated for various periods of time $(0-30 \mathrm{~min})$ at $28^{\circ} \mathrm{C}$ in YPD medium containing $1(0,0), 2$ $(\square, \square)$ or $3(\Delta, \Delta) \mu \mathrm{g}$ syringomycin $\mathrm{ml}^{-1}$, and viability of treated cells was determined as described in the legend to Fig. 2. The experiment was done three times with reproducible results. Results presented are from a representative single experiment.

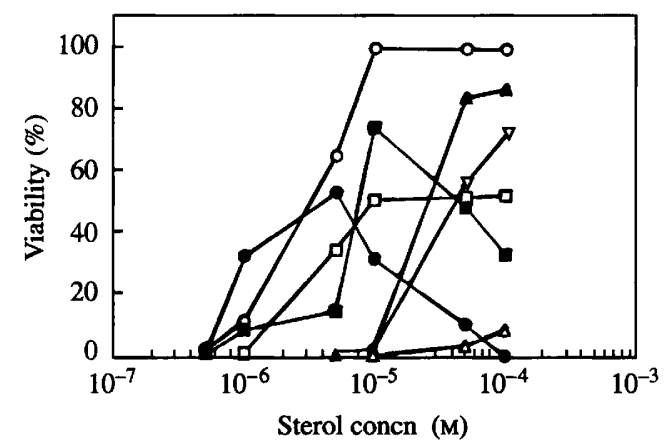

Fig. 4. Protection by sterols and other lipids against cytotoxicity of syringomycin. Cells were incubated at $28^{\circ} \mathrm{C}$ with $1 \mu \mathrm{g}$ syringomycin $\mathrm{ml}^{-1}$ and the indicated concentrations of the lipids for $30 \mathrm{~min}$ in saline, and viability of treated cells was determined as described in the legend to Fig. 2. The lipids added were as follows: cholesterol $(O)$,

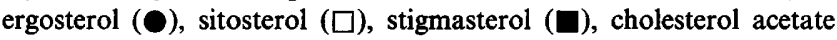
$(\triangle)$, oleic acid $(\Delta)$ and phosphatidylcholine $(\nabla)$. The experiment was done three times with reproducible results. Results presented are from a representative single experiment.

see if the cytotoxicity depends on growth phase (Fig. 3). Exponentially growing cells in YPD medium were much more sensitive to syringomycin than stationary-phase cells. However, the higher sensitivity of the exponentialphase cells was not dependent on cell division. Exponentially growing cells starved for $30 \mathrm{~min}$ at $28^{\circ} \mathrm{C}$ in saline still remained highly sensitive to the toxin (data not shown).

\section{Effect of sterols on the toxicity of syringomycin}

To see if externally added sterols protect the cells from the cytotoxicity of syringomycin, cells were treated with $1 \mu \mathrm{g}$ syringomycin $\mathrm{ml}^{-1}$ in saline for $30 \mathrm{~min}$ in the presence of various concentrations of sterols before measuring cell viability (Fig. 4). Among the sterols tested, cholesterol had the most potent effect, and the

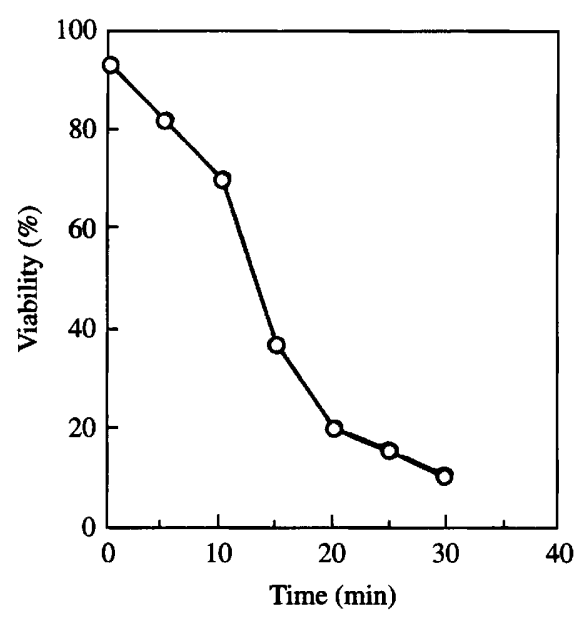

Fig. 5. Reversing effect of cholesterol against cytotoxicity of syringomycin. Syringomycin $\left(1 \mu \mathrm{g} \mathrm{ml}^{-1}\right)$ was added to cell suspensions in saline, and cholesterol $(25 \mu \mathrm{M})$ was added at different times during the incubation. The incubation of the cells with syringomycin was for $30 \mathrm{~min}$ at $28^{\circ} \mathrm{C}$. Cell viability of treated cells was determined as described in the legend to Fig. 2. The experiment was done three times with reproducible results. Results presented are from a representative single experiment.

cytotoxicity of syringomycin was completely abolished by the presence of concentrations of cholesterol of $10 \mu \mathrm{M}$ or higher. Cholesterol acetate had almost no protective effect. Ergosterol had a protective effect against syringomycin at concentrations between 1 and $10 \mu \mathrm{M}$. However, the effect of ergosterol was partial, restoring viability only in $40-60 \%$ of the treated cells. Higher concentrations of ergosterol (above $50 \mu \mathrm{M}$ ) had little protective effect, possibly due to a solubility problem. Sitosterol and stigmasterol also protected against cytotoxicity, but their effects were weaker than cholesterol, restoring viability in $50-70 \%$ of total cells. Other lipids such as phosphatidyl choline and oleic acid also had a weak protective effect, but only at very high concentrations (ca $100 \mu \mathrm{M})$.

We next examined whether externally added cholesterol could reverse the cytotoxicity induced by syringomycin. Cholesterol $(25 \mu \mathrm{M})$ was added at various times after the addition of $1 \mu \mathrm{g}$ syringomycin $\mathrm{ml}^{-1}$ in saline, and cytotoxicity was determined by colony formation on agar plates (Fig. 5). The cells were incubated with the toxin for $30 \mathrm{~min}$. When cholesterol was added to the cell suspension within $10 \mathrm{~min}$ of exposure to the toxin, it had a significant reversing effect against the toxin, restoring viability in $70 \%$ or more of the treated cells. In contrast, when cholesterol was added to the cell suspension after 20 min of exposure to the toxin, the sterol restored viability in less than $20 \%$ of the treated cells. These data are consistent with the theory that the cytotoxicity of syringomycin was established immediately after an 
exposure of the cells to the toxin, and cholesterol interferes with an initial process of the cytotoxicity.

\section{Discussion}

The present study demonstrated that the toxic effect of syringomycin on yeast is reduced in an environment containing sterols. Among the sterols tested, cholesterol was the most effective. In the presence of $25 \mu \mathrm{M}$ cholesterol, syringomycin cytotoxicity was completely abolished. Since cholesterol only gave protection during the early incubation times with syringomycin, it seems to interfere with an initial interaction of syringomycin with the cell, and does not reverse the interaction of previously bound syringomycin. These results are consistent with our hypothesis that membrane ergosterol is critical for syringomycin binding ( $N$. Taguchi and others, unpublished results).

As expected from the rapid stimulation of $\mathrm{Ca}^{2+}$ uptake by syringomycin (Takemoto et al., 1991), cytotoxicity was established within 15-20 min of exposure to the toxin. The time required for the cytotoxicity roughly corresponds to the occurrence of $\mathrm{Ca}^{2+}$ influx, suggesting that the rapid change in the ion fluxes induced by the toxin is fatal to the cell. Syringomycin was much more toxic to growing cells than to stationary-phase cells. The cytotoxicity was not cell-cycle dependent, since growing cells starved in saline were still highly sensitive to the toxin. The growth-dependent sensitivity could be attributed to differences in wall composition and thickness, as suggested for nystatin which is more toxic to growing cells having thinner cell walls as compared to thickwalled stationary-phase cells (Marini et al., 1961; Lampen et al., 1962).

The primary interaction of the toxin and sensitive cells involving membrane ergosterol may be analogous to that suggested for polyene macrolide antibiotics such as nystatin and amphotericin B. However, the structure of syringomycin is obviously different from that of the polyene antibiotics. Also, the protective effects of different sterols against the cytotoxicity of syringomycin were different from those against the polyene antibiotics where protection was more effective with ergosterol than cholesterol (Lampen, 1966). It has been suggested that membrane sterols are involved in the antifungal activity of the peptidolipidic antibiotic iturin A. The amino acid sequences of iturin $\mathrm{A}$ and syringomycin are not related to each other. The binding of iturin A to $S$. cerevisiae was dependent on the nature of sterol present in the membrane. A mutant strain containing cholesterol instead of ergosterol showed the highest affinity for iturin A (Latoud et al., 1990). The effects of various lipids, including sterols and phospholipids, as inhibitors of the antifungal activity of iturin A were examined in $S$. cerevisiae and cholesterol was found to be the strongest inhibitor (Besson et al., 1979).

Overall, the results suggest that the protective effect of sterols can be attributed to the inhibition of syringomycin interaction with the cell surface of sensitive cells, by preventing access of the toxin to the cell through physical interaction of the toxin with the exogenously added sterols. The protective effect of sterols against the action of syringomycin is consistent with our hypothesis that membrane ergosterol is a critical component for syringomycin binding as suggested by genetic studies (N. Taguchi and others, unpublished). The strong protective effect of cholesterol against the toxicity of syringomycin may offer opportunities to develop preventive agents against the phytopathogens that produce syringomycin or related phytotoxins.

This work was supported in part by a National Science Foundation grant DCB9003398 to J.Y.T.

\section{References}

Besson, F., Peypoux, F., Michel, G. \& Delcambe, L. (1979). Antifungal activity upon Saccharomyces cerevisiae of iturin A, mycosubtilin, bacillomycin and of their derivatives; inhibition of this antifungal activity by lipid antagonists. Journal of Antibiotics 32, 828-833.

BiDWA,, A. P. \& TAKemoto, J. Y. (1987). Bacterial phytotoxin syringomycin, induces a protein kinase-mediated phosphorylation of red beet plasma membrane polypeptides. Proceedings of the National Academy of Sciences of the United States of America 84, 6755-6759.

DeVay, J. E., Lukezic, F. L., Sinden, S. L., English, H. \& Coplin, D. L. (1968). A biocide produced by pathogenic isolates of Pseudomonas syringae and its possible role in the bacterial canker disease of peach trees. Phytopathology 58, 95-101.

Gross, D. C. \& DEVAY, J. E. (1977). Role of syringomycin in holcus spot of maize and systemic necrosis of cowpea caused by Pseudomonas syringae. Physiological Plant Pathology 11, 1-11.

Gross, D. C., DeVay, J. E. \& Stadman, F. (1977). Chemical properties of syringomycin and syringotoxin; toxigenic peptides produced by Pseudomonas syringae. Journal of Applied Bacteriology 43, 453-463.

LAMPDEN, J. O. (1966). Interference by polyenic antifungal antibiotics (especially nystatin and filipin) with specific membrane functions. Symposium of the Society for General Microbiology 16, 111-130.

LAMPEN, J. O., ARNow, P. M., BorowsKa, A. \& LaSkin, A. I. (1962). Location and role of sterol at nystatin-binding sites. Journal of Bacteriology 84, 1152-1160.

Latoud, C., Peypoux, F. \& Michel, G. (1990). Interaction of iturin A, a lipopeptide antibiotic, with Saccharomyces cerevisiae cells: influence of the sterol membrane composition. Canadian Journal of Microbiology 36, 384-389.

LoNGley, R. P., Rose, A. H. \& KNights, B. A. (1968). Composition of the protoplast membrane from Saccharomyces cerevisiae. Biochemical Journal 108, 401-412.

Marini, F., ARnow, P. \& LAMPEN, J. O. (1961). The effect of monovalent cations on the inhibition of yeast metabolism by nystatin. Journal of General Microbiology 24, 51-62.

REIDL, H. H. \& TAKEMOTO, J. Y. (1987). Mechanism of action of bacterial phytotoxin, syringomycin. Simultaneous measurement of early responses in yeast and maize. Biochimica et Biophysica Acta 898, 59-69.

Sinden, S. L., DeVay, J. E. \& Backman, P. A. (1971). Properties of syringomycin, a wide spectrum antibiotic and phytotoxin produced by Pseudomonas syringae, and its role in the bacterial canker disease of peach trees. Physiological Plant Pathology 1, 199-213. 
Takemoto, J. Y., Zhang, L., Taguchi, N., TaChiKaWA, T. \& MiYaKaWA, T. (1991). Mechanism of action of the phytotoxin syringomycin: a resistant mutant of Saccharomyces cerevisiae reveals an involvement of $\mathrm{Ca}^{2+}$ transport. Journal of General Microbiology 137, 653-659.

TanaKa, K., Matsumoto, K. \& Toh-E, A. (1988). Dual regulation of the expression of the polyubiquitin gene by cyclic AMP and heat shock in yeast. EMBO Journal 7, 495-502.
Zhang, L. \& TAKemoto, J. Y. (1986). Mechanism of action of Pseudomonas syringae phytotoxin, syringomycin. Interaction with the plasma membrane of wild-type and respiratory-deficient strains of Saccharomyces cerevisiae. Biochimica et Biophysica Acta 861, 201-204.

Zhang, L. \& TAKemoto, J. Y. (1987). Effect of Pseudomonas syringae phytotoxin, syringomycin, on plasma membrane fraction of Rhodotorula pilimanae. Phytopathology 77, 297-303. 